\title{
PERANAN PROMOSI DALAM MENINGKATKAN JUMLAH DANA PIHAK KETIGA PADA PT. BANK NAGARI CABANG PAINAN
}

\author{
Atika khairunnisa, Romi susanto \\ Akademi Keuangan dan Perbankan "pembangunan” Padang \\ atikakhairannisa74@gmail.com \\ romisusanto@akbpstie.ac.id
}

\begin{abstract}
The high level of competition in banks to obtain Third Party Funds (TPF), encourages banks to continue to lure customers in various ways, starting with improving operational performance, and improving services, to product diversification and the use of attractive incentive prizes. And also must try to anticipate and formulate the right strategy to win the competition in terms of collecting public funds. The purpose of this study is to determine the most appropriate strategy for Bank Nagari to conduct third party funds. The research method was carried out by referring to the strategy framework, after comparison, data was obtained from literature studies, and various other sources.
\end{abstract}

Keywords : growth strategy, third-party funds (tpf, Bank nagari

\section{PENDAHULUAN}

Persaingan dalam dunia perbankan dalam situasi pasar saat ini terus mengalami sebuah perubahan yang sangat cepat, kondisi ini bersamaan dengan sistem pasar global yang memiliki tingkat persaingan tajam di pasar domestic maupun pasar internalsional (ibn, bogor dan Bad n.d). setiap bank berlombalomba dalam menarik nasabah dan pada akhirnya nasabah mendapatkan keuntungan dari keadaan tersebut, karena itu dunia perbankan tidak mempunyai banyak pilihan kecuali dengan meningkatkan profesinalisme, kompentensi dan daya saing. Untuk itu bank harus memperhatikan kebutuhan dan keinginan nasabah karena nasabah merupakan hal yang sangat penting bagi kelancaran suatu lembaga dunia perbankan. Dimana bank sangat membutuhkan dana yang akan menunjang kemajuan suatu perusahaan atau lembaga keuangan. Dimana lembaga keungan sangat membutuhkan aliran dana, maka dari itu bank memperoleh dana tersebut dari masyarakat dan untuk masyarakat untuk memenuhi atau dapat mensejah teraan masyarakat itu sendiri. Disini menjelaskan tentang aliran dana yang di dapat oleh lembaga keuangan, masyarakat juga disebut sebagai dana pihak ketiga. Dana pihak keIII adalah merupakan dana-dana yang beerasal dari masyarakat luas, baik perorangan maupun badan usahan yang di peroleh bank dengan menggunakan berbgai instrumen produk simpanan yang memiliki oleh bank (Sukma 2013). 
Dana pihak keIII (DPK) juga dapat diartikan dana yang bersumber dari masyarakat luas merupakan sumber yang sangat penting untuk aktivitas operasional bank dan merupakan tolak ukur keberhasilan suatu bank apabila bank dapat menanggung biaya operasi dari sumber dana ini (Anggreni dan suardhika 2014). Tanpa adanya dana yang cukup, bank tidak bisa berbuat apa-apa, atau dengan kata lain yaitu bank tidak dapat berfungsi sma sekali. Oleh karena itu bank harus mampu meningkatkan dana pihak ke III agar operasional bank berjalan dengan baik.

\section{LANDASAN TEORI}

\section{Dana pihak keIII (DPK)}

Dana pihak ke III berdasrkan UU perbankan No. 10 tahun 1998 adalah dana yang di percayakan oleh masyarakat kepada bank berdasrkan perjanjian penyimpanan dana dalam bentuk giro, deposito, tabungan. Pentingnya sumber dana dari masyarakat luas, disebabkan sumber dana dari masyarakat luas merupakan sumber dana yang paling utama bagi bank. Sumber dana yang disebut juga sumber dana pihak keIII. Bentukbentuk dana pihak keIII ada tabungan, giro, deposito dapat di jelaskan dibawah ini.

a. Tabungan

Jenis tabungan yang dilakukan oleh pihak keIII yang penariknya dilakukan menurut syarat-syarat tertentu sesuai dengan perjanjian antara bank dan nasabah. Tabungan adalah simpanan yang penarikannya hanya dapat dilkukan dengn syarat-syarat tertentu yang di sepakati, tetapi tidak dapat ditarik dengan cek, bilyet giro, dan alat lainnya yang dipersamakaan dengan itu.

b. Giro

Simpanan giro merupakan simpanan yang diperoleh daari masyarakat yang sifat penarikannya adalah dapat ditarik di setiapsaat dengan dengan menggukan cek dan bilyet giroatau saranaperintah lainnya atau pemidahan bukuan.

c. Deposito

Deposito adalah simpanan yang penarikannya hanya dapat di lakukan pada waktu tertentu berdasarkan perjanjian nasabah dengan bank. Penarikan deposito dapat ditarik jika telah jatuh tempo jatuh yang telah di perjanjian antara nasabah dengn pihak bank.

\section{METODE PENELITIAN}

\section{Jenis dan Sumber data}

Penelitisn ini bersifat deskritif menggunakan analisa kualitatif, diman penelitian dilakukan dengan menganalisa dan menjelaskan proses penghimpunanan dana masyarakat, perkembagan penghimpunan dana masyarakat serta aktivitas pemasaran produk bnk dalam menigkat penghimpunan dana. Ada beberapa sumber yang dapat untuk pengambian data 
1. Sumber dana primer

Adalah sumber data yang di peroleh secara langsung dari sumber aslinya. Data ini diperoleh melalui survey, wawancara, atau membuat daftar pertanyaan yang berhubungan peranan jumlah dana pihak III.

2. Sumber data sekuler

Adalah sumber data yang di peroleh secara tidak langsung melalui media perantara. Data ini umumnya digunakan untuk melengkapi data primer berupa buku referensi dan informasi yang dimuat oleh prusahaan serta studi keperpustakaan, jurnal, dan lainnya.

\section{HASIL DAN PEMBAHASAN}

Untuk menunjang peningkatan dana pihak ketiga haarus adanya sebuah sarana agar masyarakat dapat melihat atau mengetahui tentang produk yang dikeluarkan oleh lembaga perbankan. Dengan adanya alat tersebut masyarakat tertarik untuk menanamkan dananya ke bank. Promosi salah satu alat yang dapat di andalkan karenaan promosi sangat berperan penting dalam dunia perbankan karena promosi bisa mendatangkan keuntungan karena promosi bisa di lihat oleh khalayak banyak dapat dikatakan promosi adalah salah satu variabel dalam bauran pemasaran yaang sangat penting di laksanakan oleh perusahaan dalam memasarkan produk dan jasa, promosi adalah sejenis komunikasi yang memberikan penjelasan yang menyakinkan pada calon konsumen tentang arang dan jasa. Jadi promosi salah satu bgian dari bauran pemasaran yang sangat besar peraannya. Ada beberapa tujuan melakukan promosi untuk meningkatkan dana pihak III yaitu :

a. Untuk menyebarkan informasi produk atau jasa perusahaan kepada pasar/konsumen

b. Untuk branding atau membentuk citra produk di mata para konsumen

c. Untuk membedakan dan menggulkan produknya di bandingkan dengan produk compettitor atau pesaing

d. Untuk menaikana penjualan serta laba atau keuntungan sehingga perusahaan meningkat.

e. Untuk meyebarkan luaskan informasi produk kepada calon konsumen yang potensial

f. Dan untuk membentuk citra produk atau jasa perusahaan di mata para konsumen

Bentuk-bentu mempromosikan produk bank dengan cara yaitu :

a. Advertising

1. Menggunakan media masa sebagai massifikasi pesan

2. Mmenggunakan sponsor yang teridentifikasi

3. Bersifat persuasi khalayak

4. Bertujuan meraih audiens sebanyak-banyak

5. Komunikasi

6. Nonpersonal komunikasi. 
Contoh alat digunakan Media cetak seperti koran, majalah dll. Sedangkan dengan menggunakan Elekronika seperti website, radio, televisi, dll. Dan menggunakan alat transit advertensing bullentin, poster/spanduk, stiker, dan lain-lain.

b. Personal selling

Bentuk promosi ini secara personal denga presentasi lisan dalam suaatu percakapan dengan calon pembeli yang ditunjukan untuk merasng pembeli. Penjualan tatap uka adalah kegiatan mempromosikan suatu produk dengan cara mendatangi ke tempat konsumen berada

c. Sales promosi

Alat-alat yang digunakan dalam sales promosi adalah

1. Memberikan Sampel/contoh

2. Memberikan kupon/voucher

3. Premi yaitu barang yang ditawarkan dengn harga yang rendah

4. Paket harga

5. Undian

6. Kontes

d. Publishing

Adalah upaya perusahaan untuk mendukung membina citra perusahaan yang baik, dan menaggani atau menangkal isu, cerita dan peristiwa yang dapat eerugikan perusahaan.

e. Direct marketing

Direct marketing menggunakan macam-macam media yaitu :

1. Direct email

2. Catalog

3. Broadcast

4. Infomercial

5. Tv advertorial

6. Teleeshopping

7. Print media

8. Telemarketing

9. Elektronik

10. Internet shopping

Berikut ini data laporan rekening tabunga, giro, dan deposito pada PT. Bank Nagari cabang Painan periode 2014-2017 sebagai berikut : 
Tabel 1

Data JumlahRekening Tabungan, GirodanDeposito PT. Bank

NagariCabangPainan

Periode2014-2017

\begin{tabular}{|c|c|c|c|}
\hline Tahun & $\begin{array}{c}\text { JumlahRekening } \\
\text { Tabungan }\end{array}$ & $\begin{array}{c}\text { JumlahRekening } \\
\text { Giro }\end{array}$ & $\begin{array}{c}\text { Jumlahrekening } \\
\text { Deposit }\end{array}$ \\
\hline 2014 & 104.389 & 83.478 & 60.442 \\
\hline 2015 & 133.209 & 127.022 & 74.956 \\
\hline 2016 & 113.209 & 94.546 & 37.397 \\
\hline 2017 & 130.311 & 64.364 & 60.834 \\
\hline
\end{tabular}

Sumber: PT. Bank NagariCabangPainan

Pada tahun 2014-2017 data jumlah rekening tabungan, giro dan deposito dapat dilihat pada gambar di bawah ini yang menjelaskan tentang kenaikan dan penurunan rekening simpanan deposito yang mengakibatkan jumlah deposito pada PT. Bank Nagari Cabang Painan mengalami tidak stabilan.

Gambar.1

Data JumlahRekening Tabungan, GirodanDeposito PT. Bank Nagari CabangPainan

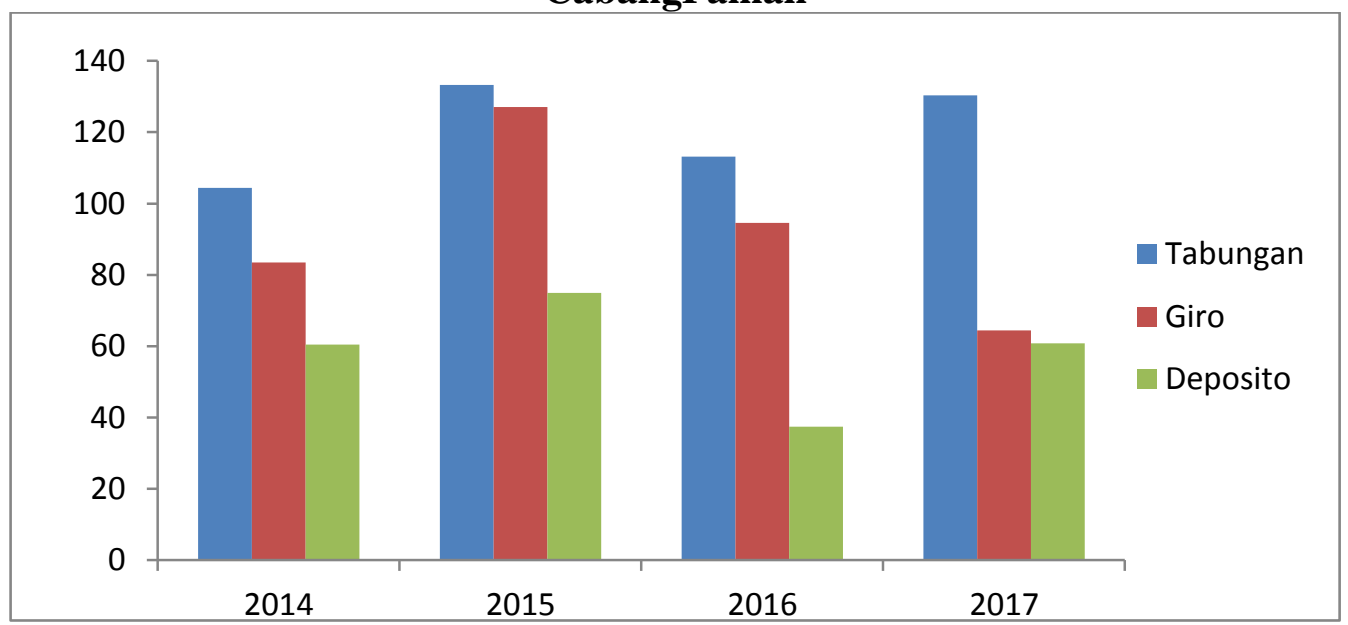

Sumber: PT. Bank NagariCabangPainan

Berdasarkan tabel diatas dapat diuraikan perkembangan jumlah nasabah tabungan, giro dan deposito PT. Bank Nagari Cabang painan pada tahun 2014 jumlah rekening tabungan sebesar 104.389 orang, untuk rekening giro sebesar 83.478 orang sedangkan dengan jumlah rekening deposito sebesar 60.442 orang, pada tahun 2015 jumlah rekenig tabungan 133.209 orang, untuk rekening giro sebesar 127.022 orang dan dengan jumlah untuk rekening deposito 74.956 orang, pada tahun 2016 jumlah rekening tabungan sebesar 113.209 orang,untuk jumlah rekening giro sebesar 94.546 orang dan dengan jumlah untuk rekening deposito sebesar 37.397 orang, dan pada tahun 
2017 jumlah rekening tabungan 130.311 orang, untuk giro jumlah rekening sebesar 64.364 dan untuk jumlah rekening deposito sebesar 60.834 orang.

Dapat kita simpulakan pada tahun 2014 ke tahun 2015 untuk jumlah rekening tabungan, giro dan deposito mengalami peningkatan. Kemudian untuk tahun 2015 ke tahun 2016 jumlah rekening tabungan giro dan deposito mengalami penurunan. Dan pada tahun 2016 ke tahun 2017 jumlah rekening tabungan mengalami peningkatan berbeda dengan giro dan deposito masih mengalami penurunan.

\section{KESIMPULAN}

Dari pembahasan yang telah dilakukan tentang "Perananan Promosi Dalam Meningkatkan Jumlah Jumlah Dana Pihak ke III Pada PT. Bank Nagari Cabang Paianan.Berdasarkan uraian pada bab-bab sebelumnya, maka dapat diambil kesimpulan sebagai berikut :

1. Untuk melakukan aktivitas promosi dalam meningkatkan dana pihak ketigaPT. Bank Cabang Painan Pesisir Selatan telah melakukan promosi penjualan (sales promotion) dan penjualan perorangan (personal selling) seperti memberi hadiah kepada nasabah lama guna menghindari nasabah berpindah ke bank lain.

2. Aktivitas promosi yang dilakukan terdapat penurunan pada jumlah rekeningdeposito 2016 karena aktivitas promosi hanya ditargetkan kepada beberapa orang atau orang tertentu saja. Dan pada jumlah rekening tabungan terjadi peningkatan karena adanya sikoci dan tabunganku yang dilakukan oleh PT. Bank Bank Nagari Cabang Painan Pesisir Selatan.

3. Dari hasil penelitian yang telah dilakukan PT. Bank Nagari Cabang Painan Pesisir Selatan sudah sepenuhnya menerapkan aktivitas promosi seperti produk sikoci dan tabunganku.

\section{UCAPAN TERIMAKASIH}

1. Ibunda Eliyurnis Kakak-kakakku tercinta yang telah memberikan dukungan motivasi baik itu materi maupun moral.

2. IbuAfriyeni, SE, MM, selaku Direktur Akademi Keuangan Dan Perbankan "Pembangunan" Padang.

3. Bapak Doni Marlius, SE, MM selaku ketua prodi Akademi Keuangan dan Perbankan "Pembangunan" Padang.

4. Bapak Romi Susanto, SE, MM, selaku dosen pembimbing tugas akhir yang senantiasa membimbing, memberi arahan dan dukungan sehingga penulis dapat menyelesaikan tugas akhir ini dengan baik.

5. Bapak dan Ibu dosen Program Studi Keuangan akademi.

6. Kepada senior-senior yang sudah memberikan nasehat dan motivasi.

7. Teman-teman, dan semua pihak yang telah memberikan dukungan dan saling menyemangati satu sama lain dalam penulisan Tugas Akhir ini. 


\section{DAFTAR PUSTAKA}

Anggreni, Made Ria, dan I Made Sadha Suardhika. 2014. "Pengaruh Dana PihakKetiga, Kecukupan Modal, Resiko Kredit Dan Suku Bunga Kredit Pada Profitabilitas." E-Jurnal Manajemen Universitas Udayana (ISSN: 2302-8556) 1: 27-37.

Fernandes, Y. D., \& Marlius, D. (2018). Peranan Customer Service Dalam Meningkatkan Pelayanan Kepada Nasabah Pada PT. Bank Pembangunan Daerah Sumatera Barat Cabang Utama Padang. https://doi.org/10.31227/osf.io/wrh3p

Hidayati, R. R., \& Marlius, D. (2018). Aktivitas Promosi Dalam Meningkatkan Dana Pihak Ketiga Pada PT. Bank Perkreditan Rakyat (BPR) Batang Kapas Pesisir Selatan. https://doi.org/10.31227/osf.io/8dgqn

Jefri Arif Nurmansyah. 2009. Penerapan Bauran Promosi Dalam Meningkatkan Jumlah Nasabah Pada Bank Rakyat Indonesia Unit Wonosari I Klaten. Mycological Research 113(2): 207-21.

Grünig, C. R., Queloz, V., Duò, A., \& Sieber, T. N. (2009). [ No Title ]. Mycological Research, 113(2), 207-221.

Marlius, D. (2016). Pengaruh Bauran Pemasaran Jasa Terhadap Minat Nasabah Dalam Menabung Pada Bank Nagari Cabang Muaralabuh. https://doi.org/10.31227/osf.io/vdqgx

Safitri, R. N., \& Marlius, D. (2017). Penerapan E-Banking Dalam Meningkatkan Jasa Dan Layanan Perbankan Di PT. Bank Rakyat Indonesia Cabang Padang. https://doi.org/10.31227/osf.io/gkv8t

Widayati, R. (2019). Aktivitas Pemasaran Produk Simpanan PT. Bank Tabungan Negara (Persero)Tbk Kantor Cabang Padang. https://doi.org/10.17605/OSF.IO/3Z5YC

Widayati, R. (2019). Aktivitas Pemasaran Produk Tabungan Pada PT. Bpr Rangkiang Denai Payakumbuh Barat. https://doi.org/10.17605/OSF.IO/S3UZM 